BNL-52647

Formal Report

\title{
USING PERFLUOROCARBON TRACERS FOR VERIFICATION OF CAP AND COVER SYSTEMS PERFORMANCE
}

\author{
J. Heiser and T. Sullivan
}

November 2001

\begin{abstract}
Environmental Sciences Department
Brookhaven National Laboratory

Brookhaven Science Associates

Upton, Long Island, New York 11973
\end{abstract}

Under Contract No. DE-AC02-98CH10886 with the

UNITED STATES DEPARTMENT OF ENERGY 


\section{DISCLAIMER}

This report was prepared as an account of work sponsored by an agency of the United States Government. Neither the United State Government nor any agency thereof, nor any of their employees, not any of their contractors, subcontractors, or their employees, makes any warranty, express or implied, or assumes any legal liability or responsibility for the accuracy, completeness, or usefulness of any information, apparatus, product, or process disclosed, or represents that its use would not infringe privately owned rights. Reference herein to any specific commercial product, process, or service by trade name, trademark, manufacturer, or otherwise, does not necessarily constitute or imply its endorsement, recommendation, or favoring by the United States Government or any agency, contractor, or subcontractor thereof. The views and opinions of authors expressed herein do not necessarily state or reflect those of the United States Government or any agency, contractor or subcontractor thereof. 


\section{EXECUTIVE SUMMARY}

The expanded use of caps and cover systems is an important aspect of the U.S. Department of Energy Environmental Management's (DOE EM) strategy for restoration and long-term stewardship of sites throughout the complex. However, very little is available in terms of long-term monitoring of covers other than downstream groundwater or surface water monitoring. By its very nature, this can only indicate that failure of the cover system has already occurred and contaminants have been transported away from the site. This is unacceptable. Methods that indicate early cover failure (prior to contaminant release) or predict approaching cover failure are needed.

The Environmental Research and Technology Division at Brookhaven National Laboratory developed a novel methodology for verifying and monitoring subsurface barriers. The technology uses perfluorocarbon tracers (PFTs) to determine flaws (e.g., holes or cracks) and high permeability areas in the barrier. Gaseous tracers are injected on one side of the barrier and searched for on the opposite side of the barrier. PFTs allow locating and sizing of leaks, have a resolution of fractions of an inch, and have been used in a variety of soils.

The capability for leak detection in subsurface barriers using PFTs has been proven at multiple demonstrations. Adaptation of this concept to covers is a necessary step prior to full-scale demonstration. This paper details the proof-of-concept testing on the use of PFTs to measure cover performance. The tests were conducted at the Savannah River Site Bentonite Mat Test Facility. The main objective of this program was to demonstrate that PFTs can be used to accurately and quickly locate flaws in a cover system. To this end, PFTs were used to verify the integrity of the geosynthetic/geomembrame composite layer of the Bentomat Test Pad. A secondary objective was to demonstrate a field-deployable PFT detection system. The system consisted of a dual trap gas chromatograph and a compositing sampling approach.

In August 2001 installation of the injection and monitoring system was completed and verification of the cover began. After the first two days of sampling and analysis, the data showed that the hydraulic barrier was intact. At this point, three induced flaws (1 1/4" diameter) were engineered into the cover. Two flaws were seen within three hours of their creation, while all three flaws were detectable within one day of introduction of the flaws. The results were repeatable day to day and were confirmed by two separate tracers.

The proof-of-concept testing at SRS was successful. The Bentomat test pad represented a worst case scenario for tracer verification of covers as the design maximized barometric pumping, wind, and atmospheric dilution effects. In addition, the use of the field deployable gas chromatograph PFT detector was successfully demonstrated. This unit was able to analyze samples on a four minute cycle down to levels of a few parts per trillion. This provided almost six orders of magnitude span between concentrations below the cover (a few ppm) and the minimum detection limit, which is more than sufficient to accurately determine the presence of a leak. The multiple tracers available with PFTs (and not with competing systems) allow greater flexibility in experimental/installation design, yield redundant (re: confirmatory) data

and give information on internal transport pathways not available from single tracer systems. This advantage is magnified when the PFT technology is applied to multi-layer cover systems. 


\section{TABLE OF CONTENTS}

EXECUTIVE SUMMARY $\ldots \ldots \ldots \ldots \ldots \ldots \ldots \ldots \ldots \ldots \ldots \ldots \ldots \ldots \ldots \ldots$

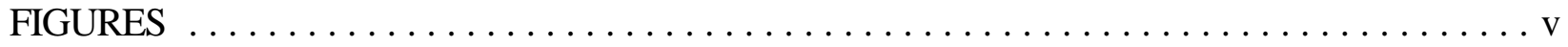

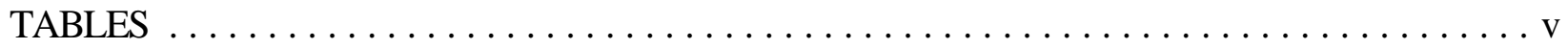

INTRODUCTION $\ldots \ldots \ldots \ldots \ldots \ldots \ldots \ldots \ldots \ldots \ldots \ldots \ldots \ldots \ldots \ldots \ldots \ldots$

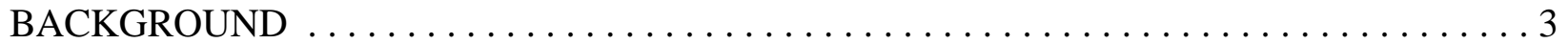

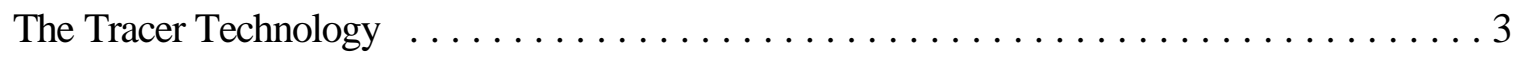

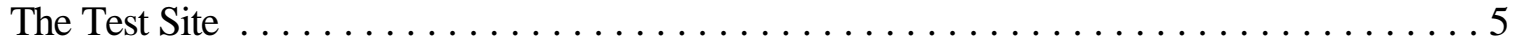

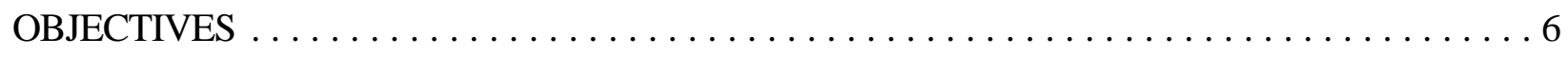

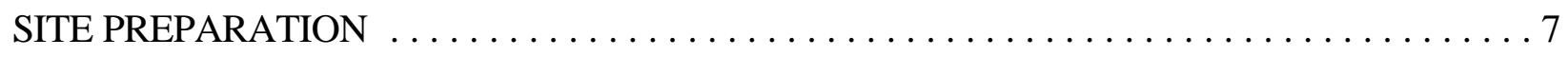

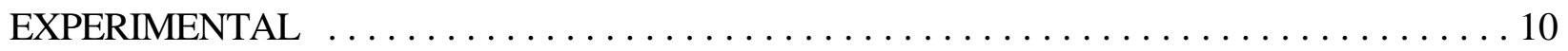

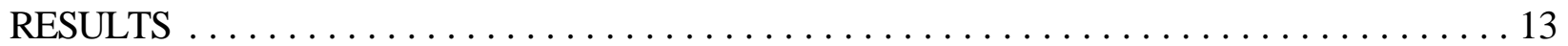

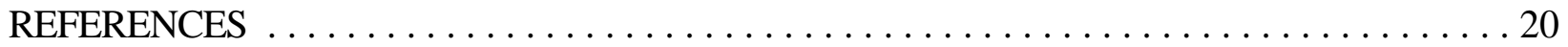




\section{FIGURES}

Figure 1 Perfluorocarbon tracer technology used to verify and monitor cover system

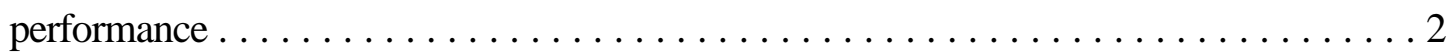

Figure 2 Laboratory gas chromatograph used for PFT analysis $\ldots \ldots \ldots \ldots \ldots \ldots \ldots \ldots$

Figure 3 Aerial view of the Savannah River Plant Bentonite Cap demonstration facility . . . . . . . 6

Figure 4 Schematic of the Bentomat Test Cap [Vertical dimensions expanded 5x for clarity . . . . . . . . . . . . . . . . . . . 7

Figure 5 Plan view of the Bentomat Test Pad with schematic overlay of details $\ldots \ldots \ldots \ldots$

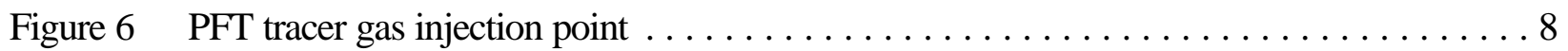

Figure 7 Sample port locations and tracer injections points for the Bentomat cover

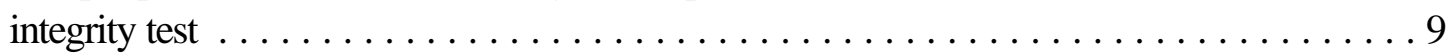

Figure 8 Sampling the soil gases for PFTs using a battery powered pump and gas sampling bags . . . . . . . . . . . . . . . . . . . 9

Figure 9 Portable Dual-Trap, Gas Chrmatograph used to measure perfluorocarbon

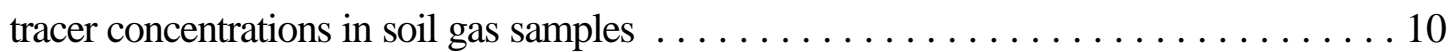

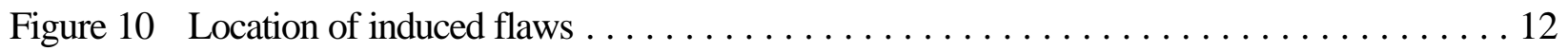

Figure 11 Plan view schematic of Bentomat Cover with PFT concentrations

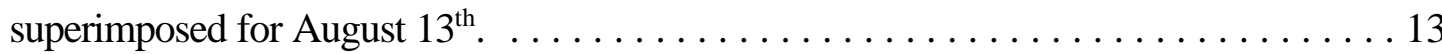

Figure 12 Schematic of Bentomat Cover with PFT concentrations. Note dark blue points are non-detects and external to the geosynthetic clay liner.

Pink is high concentration (>1.0 ppm) of PFTs and is confined to the internals

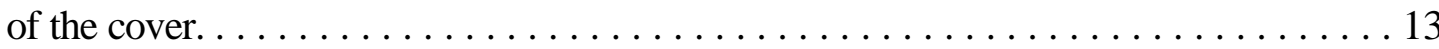

Figure 13 Plan view of cover system with measured PFT concentrations $(<0.01 \mathrm{ppb})$

at all locations. Injection of tracers beneath the cover depicted in purple $(\mathrm{PMCH})$, red $(\mathrm{PMCP})$, and green $(\mathrm{ocPDCH}) \ldots \ldots \ldots \ldots \ldots \ldots \ldots \ldots \ldots$

Figure 14 Side view of cover system with measured concentrations above the liner in blue $(<0.01 \mathrm{ppb})$ and below the liner in pink $(1 \mathrm{ppm}) \ldots \ldots \ldots \ldots \ldots \ldots$

Figure 15 Plan view on August $15^{\text {th }}$ after flaws introduced in the Bentomat liner.

Orange/red dots indicate location of flaws, green dots indicate detection

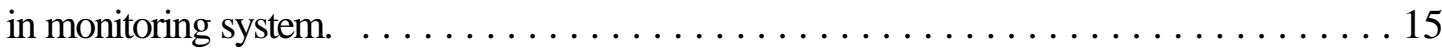

Figure 16 Side view of PFT data on August $15^{\text {th }}$ after introduction of flaws.

Color coded sphere below the cover mark flaw locations $\ldots \ldots \ldots \ldots \ldots \ldots$

Figure 17 Plan view schematic of Bentomat Cover with PFT concentration

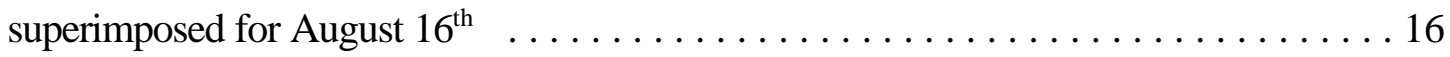

Figure 18 Schematic of Bentomat Cover with PFT concentrations for August $16^{\text {th }} \ldots \ldots \ldots 17$

Figure 19 Comparison of PMCH and PMCP tracer concentrations on August $16^{\text {th }} \ldots \ldots \ldots 17$

\section{TABLES}

Table 1 Tracers available for the BNL Cover Verification/Monitoring Technology $\ldots \ldots \ldots \ldots 3$ 


\title{
USING PERFLUOROCARBON TRACERS FOR VERIFICATION OF CAP AND COVER SYSTEMS PERFORMANCE
}

\author{
John Heiser and Terrence Sullivan \\ Environmental and Waste Management Group \\ Environmental Research and Technology Division \\ Environmental Sciences Department \\ Brookhaven National Laboratory
}

\section{INTRODUCTION}

The Department of Energy (DOE) Environmental Management (EM) office has committed itself to an accelerated cleanup of its national facilities. The goal is to have much of the DOE legacy waste sites remediated by 2006. This includes closure of several sites (e.g., Rocky Flats and Fernald). With the increased focus on accelerated cleanup, there has been considerable concernabout long-term stewardship issues in general, and verification and long-term monitoring (LTM) of caps and covers, in particular. Cap and cover systems (covers) are vital remedial options that will be extensively used in meeting these 2006 cleanup goals. Every buried waste site within the DOE complex will require some form of cover system. These covers are expected to last from 100 to 1000 years or more. The stakeholders can be expected to focus on system durability and sustained performance.

DOE EM has set up a national committee of experts to develop a long-term capping (LTC) guidance document. Covers are subject to subsidence, erosion, desiccation, animal intrusion, plant root infiltration, etc., all of which will affect the overall performance of the cover. Very little is available in terms of longterm monitoring other than downstream groundwater or surface water monitoring. By its very nature, this can only indicate that failure of the cover system has already occurred and contaminants have been transported away from the site. This is unacceptable. Methods that indicate early cover failure (prior to contaminant release) or predict approaching cover failure are needed. The LTC committee has identified predictive monitoring technologies as a high priority need for DOE, both for new covers as well as existing covers. The same committee identified a Brookhaven National Laboratory (BNL) technology as one approach that may be capable of meeting the requirements for LTM.

The Environmental Research and Technology Division (ERTD) at BNL developed a novel methodology for verifying and monitoring subsurface barriers $(1,2)$. The technology uses perfluorocarbon tracers (PFTs) to determine flaws (e.g., holes or cracks) and high permeability areas in subsurface barriers. Gaseous tracers are injected on one side of the barrier and searched for on the opposite side of the barrier. The sampling grid, concentration, and time of arrival of the tracer(s) on the opposite side are used to determine the size and location of flaws and relative permeability of the barrier. In addition, there are multiple tracers available, which allows different tracers to be injected in different quadrants of the barrier. This yields additional information on transport phenomena of the barrier. 
The technology grew from earlier work at BNL using PFTs in atmospheric and oceanographic studies which in turn lead to a variety of applications including detecting leaks in buried natural gas pipelines and locating radon ingress pathways in residential basements $(3,4)$. PFTs have regulatory acceptance and are used commercially (e.g. detecting leaks in underground power cable systems). PFTs allow locating and sizing of leaks at depth, have a resolution of fractions of an inch, and have been used in a variety of soils.

The barrier verification technology has been of interest to DOE EM and was developed with funding through the Office of Science and Technology (OST) Subsurface Contaminants Focus Area (SCFA). As a barrier verification technology, PFTs have proven to be more capable than competing systems. The use of PFTs for cover verification is a natural extension of the successful use of PFTs to verify and monitor subsurface barriers. The cover can be looked upon as a horizontal barrier. The gaseous tracer is released below the cover and detected above it (see conceptual model in Figure 1). The difficulty (compared to subsurface barriers) lies in the close proximity to the surface atmosphere. For example, barometric pumping and dilution effects are negligible for subsurface barriers but can be significant phenomena for covers.

The capability for leak detection in subsurface barriers using PFTs has been proven at multiple demonstrations. Adaptation of this concept to covers is a necessary step prior to full-scale demonstration. This paper details the proof-of-concept testing on the use of PFTs to measure cover performance. The tests were conducted at the Savannah River Site (SRS) where several field test sites withengineered covers exist. Some of these covers have been in place for almost thirty years and are well characterized and as such provided an ideal test bed for the PFT technology.

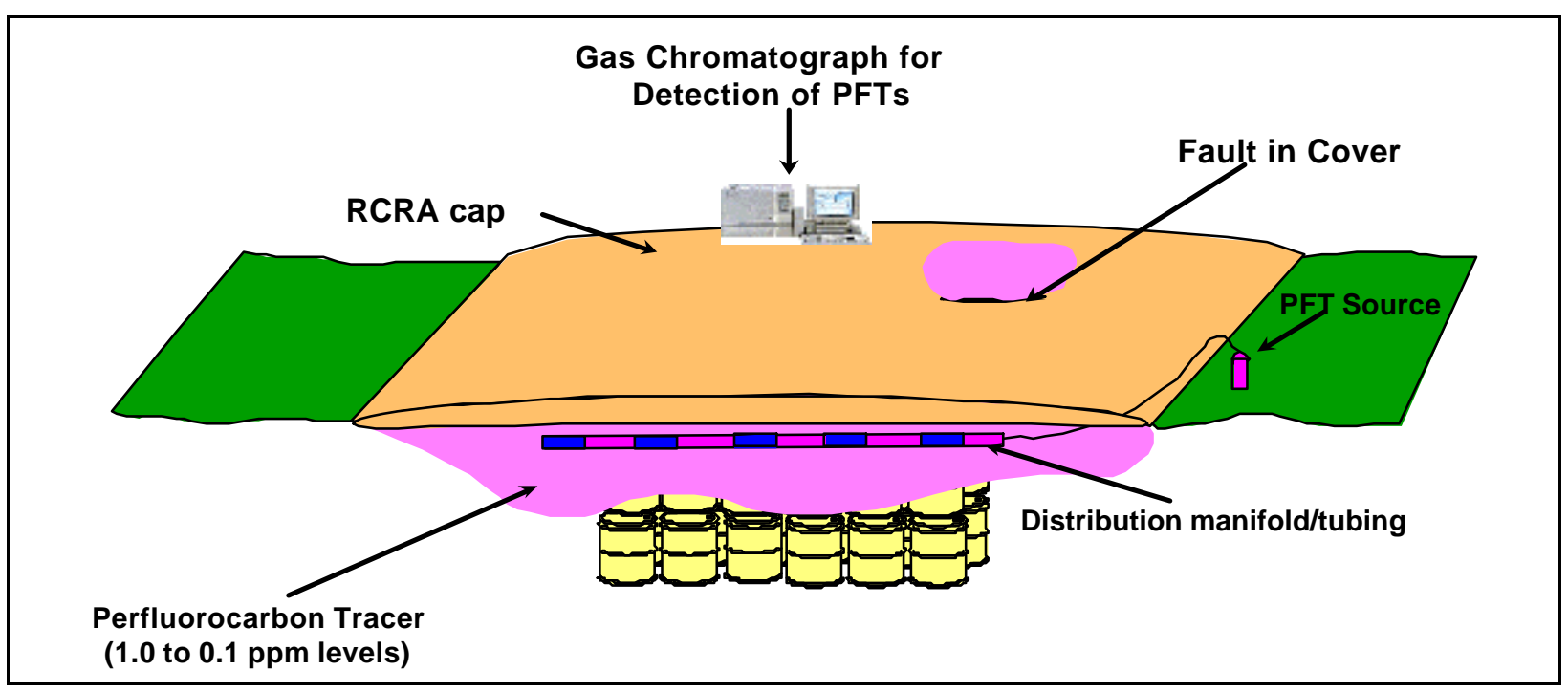

Figure 1 Perfluorocarbon tracer technology used to verify and monitor cover system performance. 


\section{BACKGROUND}

\section{The Tracer Technology}

PFTs can be detected at extremely low levels with parts per quadrillion routinely measured. This allows detection of breaches in the barrier on the order of fractions of an inch. Typically, the source injection zone concentration is on the order of 0.1 to $1.0 \mathrm{ppm}$ and leak/fault zone concentrations range from 0.1 to 100 $\mathrm{ppb}$. The tracers (see Table 1) used have already been approved for use in atmospheric, oceanographic, and leak detection (for buried gas lines and fluid-filled dielectric cables). They were also approved for subsurface barrier testing by local regulators at the Waldo New Mexico Subsurface Barrier Test site. The materials are environmentally benign and no PFT-specific ES\&H concerns have been encountered. A rudimentaryenvironmentalimpact statement for PFTs as tracers was established whichaddresses concerns about greenhouse gas and ozone layer depletion. In summary, the tracers pose no real threat in the low amounts used in each test. Flow rates generally run around 15 to $50 \mathrm{cc} / \mathrm{min}$ at 100 to $400 \mathrm{ppm}$ and flow is continued for 3 to 7 days. The total mass of PFT injected over the duration of an experiment is typically a few grams. Analysis of the PFTs is by Gas Chromatograph (Figure 2), either a laboratory unit or a field unit, which is slightly less accurate but very rugged.

Table 1. Tracers available for the BNL Cover Verification/Monitoring Technology

\begin{tabular}{|c|l|l|}
\hline Chemical Acronym & Chemical Name & Chemical Formula \\
\hline PDCB & Perfluorodimethylcyclobutane & $\mathrm{C}_{6} \mathrm{~F}_{12}$ \\
\hline PMCP & Perfluoromethylcyclopentane & $\mathrm{C}_{6} \mathrm{~F}_{12}$ \\
\hline PMCH & Perfluoromethylcyclohexane & $\mathrm{C}_{7} \mathrm{~F}_{14}$ \\
\hline pt-PDCH & Perfluorotrans 1,4 dimethylcyclohexane & $\mathrm{C}_{8} \mathrm{~F}_{16}$ \\
\hline oc-PDCH & ortho-cis-perfluorodimethylcyclohexane & $\mathrm{C}_{8} \mathrm{~F}_{16}$ \\
\hline PTCH & Perfluorotrimethylcyclohexane & $\mathrm{C}_{9} \mathrm{~F}_{18}$ \\
\hline
\end{tabular}

The injection and monitoring of the tracers can be accomplished in several manners. The ultimate goal for covers is to use long sampling lines with multiple sample/injections ports on each line (i.e., every one or two feet) and triangulation methods to determine breach/flaw location. It is envisioned that the sample and injection lines will be attached to geomembranes/geotextiles prior to installation. The lines would be attached in a criss-cross fashion to give complete coverage of the site and allow accurate triangulation. This detailed subsurface method may be used in conjunction with a cheaper, faster, but less accurate "broadband" monitoring technique. In this case, air samples are taken on a widely spaced grid pattern (e.g., 50 feet apart). The samples will be taken over longer periods to allow detection of small and/or distant leaks to be seen. If no tracers (or insignificant amounts) are seen, the cover is functioning as expected. If a sample comes up positive for tracers, the aforementioned close-spacing, high-accuracy sampling method is deployed. 


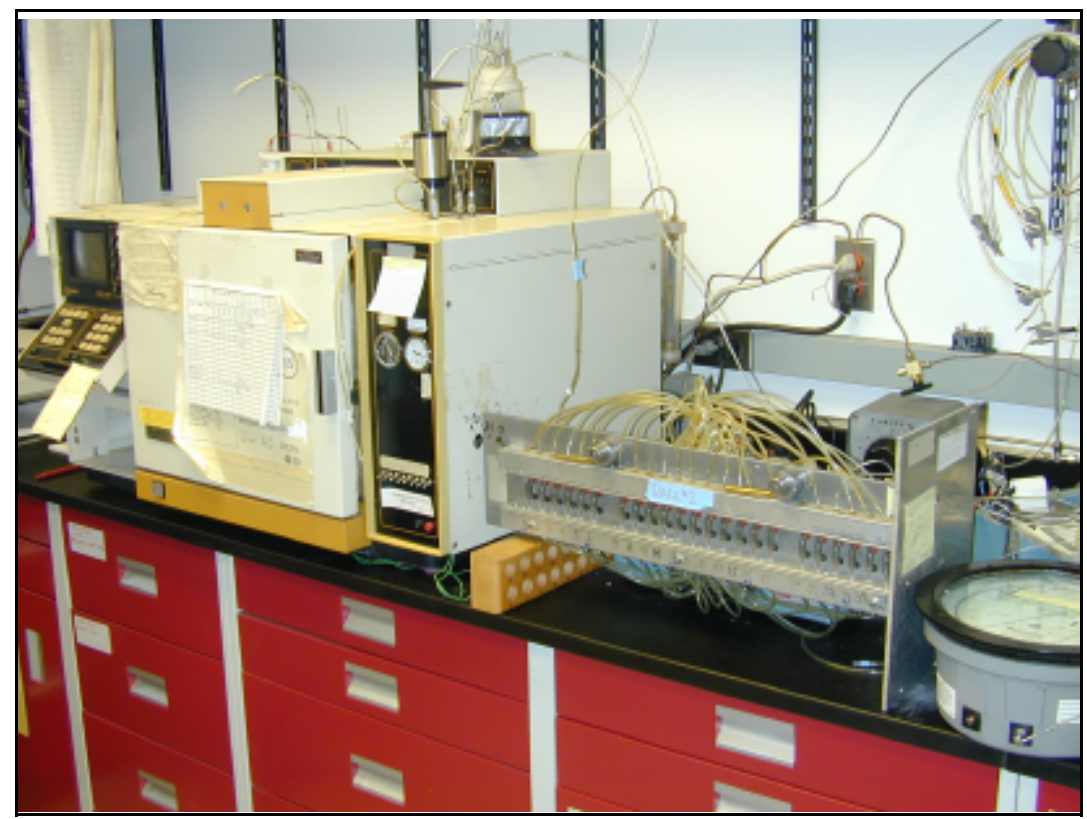

Figure 2 Laboratory gas chromatograph used for PFT analysis.

For pre-existing covers a more simplistic approach can be used. Gas sampling ports are placed in the vadose zone just above the cover and injection ports/lines are installed below the cover. Installation typically uses a penetrometer (e.g., geoprobe with $3 / 4$ to 1 " rods) and simple, low-cost monitoring methods, such as vadose zone air sample monitoring. This requires more samples to be taken but can be just as accurate and is very inexpensive to install. A comparison of installation costs and sample analysis cost would need to be performed to optimize the system.

In addition, for multilayer covers a unique tracer can be injected into each layer. Monitoring of the various layers could be used to track the potential flow pathways through each layer. This would provide a more complete and accurate understanding of barrier performance.

The amount and type of tracer and detection location on the monitoring side of the cover will determine the size and location of a breach. It is easy to see that the larger the opening in a cover, the greater the amount of tracer transported across the barrier. Locating the breach requires more sophistication in the tracer testing and data analysis methodology. Time of arrival and comparative concentration contouring can be used and multiple tracer types can be injected at different points along the barrier. Investigation of the spectra of tracers coming through a breach combined with numerical modeling of PFT transport then gives a location relative to the various tracer injection points.

Obviously, tracers can be used to verify placement continuity of a cover and to recheck corrective actions that may be used to seal or repair a breach. PFTs may also be useful to monitor a cover performance and to determine its long-term integrity. A "snapshot" of the initial transport performance of a given cover can be taken during the early performance period and then compared to future "snapshots". If for instance, the 
tracer flux increases as the cover ages it would be a signal that some property of the cover may be degrading and further investigation is warranted.

\section{The Test Site}

The Bentonite Mat Demonstration was established to provide data on alternative cover systems at the SRS. The test facility pads consisted of (bottom to top) a 4 foot loose sand layer, 1 foot separation layer (silty soil), 2 feet of compacted sandy clay layer (local soils), a composite geosynthetic clay liner/geomembrane layer (except the control pad) and a 1-2 feet cover soil layer. Four test pads (see Figure 3) were constructed: a Control Test Pad, and three test pads with geosynthetic clay liners (Gundseal ${ }^{\circledR}$, Claymax ${ }^{\circledR}$, and Bentomat $\left.{ }^{\circledR}\right)$. The three geosynthetic liner test pads were also covered by a 40 mil Gundline ${ }^{\circledR} \mathrm{HD}$ smooth High Density Polyethylene (HDPE) geomembrane. Each pad was covered with a final layer (1-2 feet) of soil. The demonstration facility was also used to study effects of induced subsidence on the performance of the cover systems. The Bentomat Test Pad was chosen for the PFT verification study and had large areas of induced subsidence as well as having large voids in the sand layer beneath the geosynthetic liner. Test pad dimensions were nominally 50 feet $x 136$ feet $x 8$ feet. A full description of the test pads and materials properties (e.g., clay content, grain size) can be found in "Bentonite Mat Demonstration Final Report" (5). The Bentomat Test Pad used a $6.4 \mathrm{~mm}$ thick, Bentomat@ SS layer consisting of a layer of sodium bentonite clay encapsulated between a woven polypropylene geotextile (upper side) and an unwoven polypropylene geotextile (bottom side). The hydraulic conductivity of this layer is reported as $5 \times 10^{-9} \mathrm{~cm} / \mathrm{sec}$. Overlying the Bentomat ${ }^{\circledR}$ layer was a $1 \mathrm{~mm}$ thick (40 mil) HDPE flexible membrane liner from Gundle Lining Systems. The reported hydraulic conductivity of the HDPE liner $2.7 \times 10^{-13} \mathrm{~cm} / \mathrm{s}$ (via ASTM E96). The geosynthetic materials also required seaming and these areas represented "areas of concern" for possible leakage.

Each test pad had a series of access pipes embedded into the sand layer to allow excavation of some of the sand for the induced subsidence testing. The Bentomat ${ }^{\circledR}$ pad had five clusters of five nominally one foot diameter pipes embedded on each side (long axis) of the cover. The pipes were stated to be 10 feet long (conversation with site manager/PI). The depth into the sand layer was extended during the induced subsidence activities (sand removal). The penetration length, as measured during the field activities for the PFT trials, was nominally 26 feet for all of the six clusters measured (the southern most three on the east slope and the southern most three on the west slope). These penetrations were used as the injection points for the tracers (described later). 


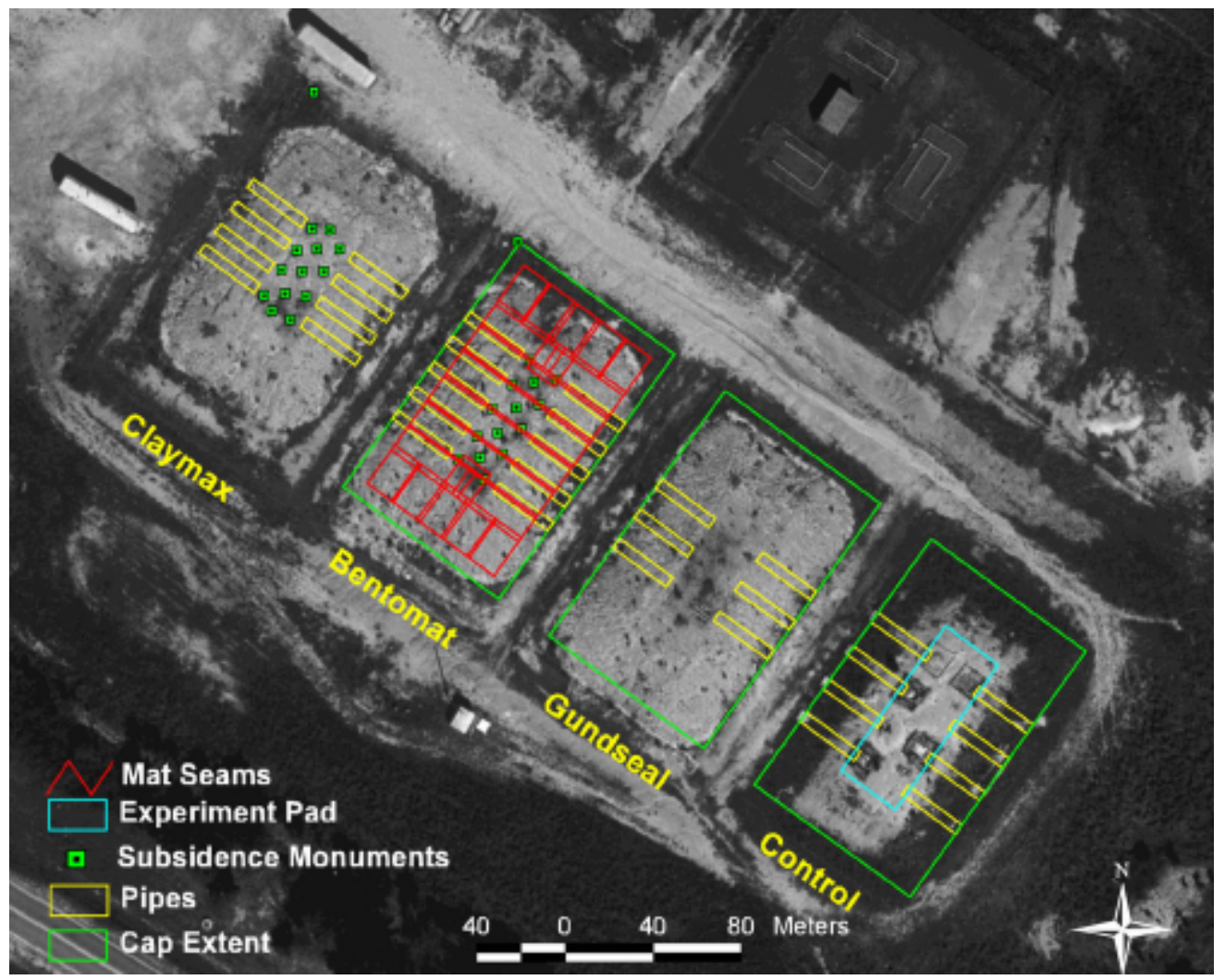

Figure 3 Aerial view of the Savannah River Plant Bentonite Cap demonstration facility.

\section{OBJECTIVES}

The main objective of this program was to demonstrate that PFTs can be used to accurately and quickly locate flaws in a cover system. To this end, PFTs were used to verify the integrity of the part of the geosynthetic/geomembrame composite layer of the Bentomat Test Pad. Our approach was to install tracer injection lines below the composite layer and monitor for the tracers in the soils above the layer. This was a very conservative test (aggressive test of the PFT technology) as the Bentomat Test Pad has only 1 to 2 feet of cover soil. This means that barometric pumping and dilution effects would be maximized. The tracers diffuse to the surface after only 2 feet of travel making horizontal travel minimal past the two foot boundary.

A secondary objective was to demonstrate a field deployable PFT detection system. The system consisted of a dual trap gas chromatograph and a compositing sampling approach (multiple soil-gas samples were combined and sampled as one composite). 


\section{SITE PREPARATION}

A simplified schematic of the Bentomat Test Pad is shown in Figure 4. The figure was used in the data interpretation and is exaggerated five times in the vertical dimensions for clarity. The proof-of-concept test of the PFT technology utilized 60\% of the top surface of the test pad (see Figure 5). The remaining portion of the pad was left undisturbed for future evaluation of the pad. Figure 5 is an aerial plan view of the test site with a schematic overlay showing the geotextiles seams (red), the excavation pipe clusters (yellow), subsidence landmarks (green) and the PFT test region (light blue with white outline). The tracer injection points are labeled A, B, and C. Three tracers were used in the study and each tracer was injection into a given zone from both the east and west sides of the cover. The two-sided injection scheme was used to obtain a more uniform tracer concentration under the cover and to minimize injection times.

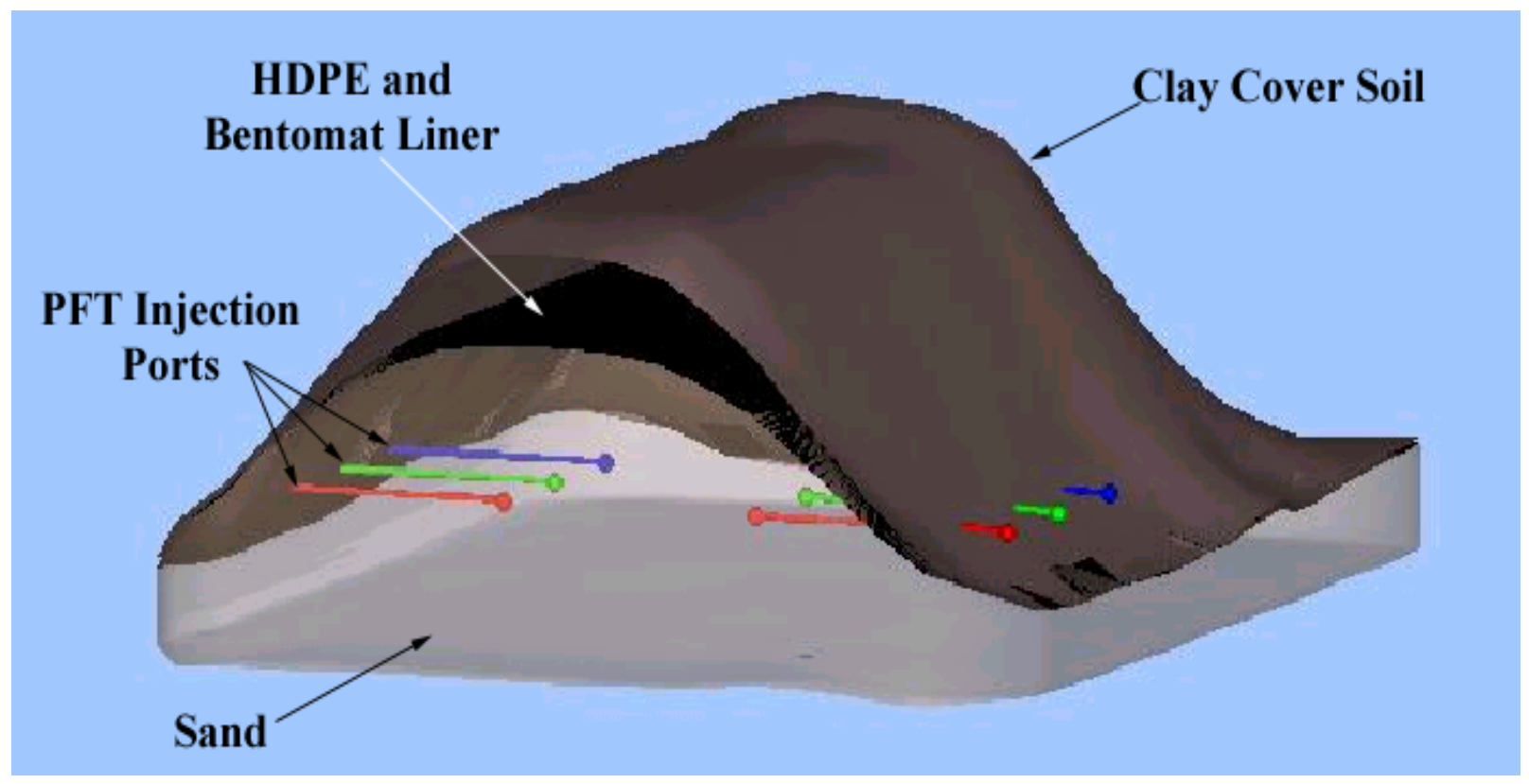

Figure 4 Schematic of the Bentomat Test Cap [Vertical dimensions expanded 5x for clarity].

The PFT injection ports consisted of $1 / 4$ " copper tubing inserted into the excavation pipe clusters. One injection tube was inserted 26 feet into each of the southern most six clusters. The tubing extended through a PVC cap that sealed off the open end of the excavation pipe. The remaining four pipes of each cluster were sealed with polyethylene end caps. Figure 6 depicts one of the injection sites with a tracer tank attached to the injection tubing. Monitoring ports were installed on top of the cover. Simple gas sampling ports were constructed from sintered glass filters attached to C "polypropylene tubing. A $1 / 2$ " rod was driven 12 to 18" into the ground (topside of the cover within the PFT test area, Figure 5) and removed. This left a hole that the glass filter and tubing were lowered into. Once the sample port was lowered to the desired depth the hole was backfilled with sand to minimize advection. The sampling port was placed just above the HDPE geomembrane ( $\left.6^{\prime \prime}\right)$. The end of the polypropylene tubing extended out of the soil and 
was attached to a pump to perform soil gas sampling. Ports were placed every five feet north to south and east to west. This resulted in a total of 84 sampling points. The planar location and labeling scheme of the monitoring ports and injection points (with tracer type) are given in Figure 7.

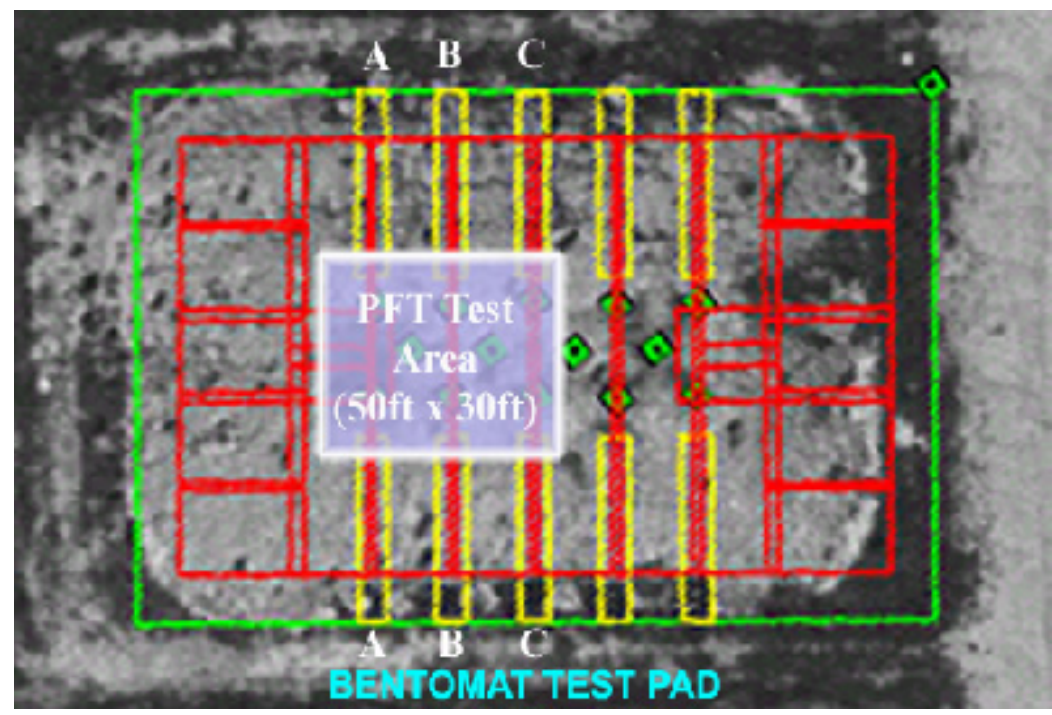

Figure 5 Plan view of the Bentomat Test Pad with schematic overlay of details.

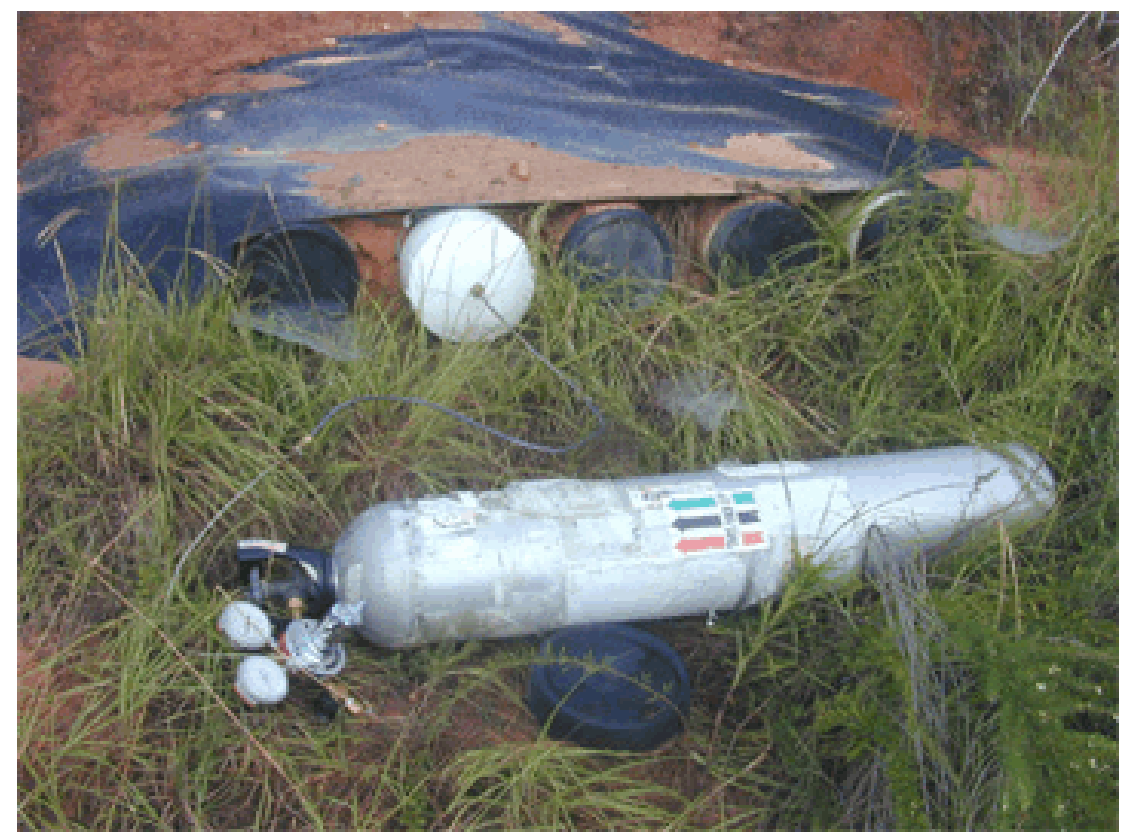

Figure 6 PFT tracer gas injection point. 


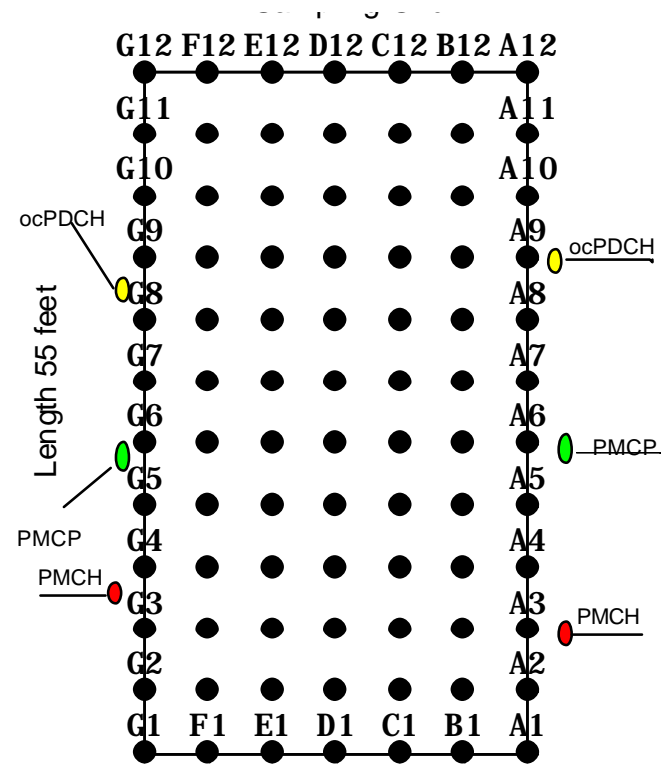

Width 30 feet

Figure 7 Sample port locations and tracer injection points for the Bentomat cover integrity test.

concentration of $1600 \mathrm{ppm}$. Sections 5 to 7 had PMCP injected at $44 \mathrm{~mL} / \mathrm{min}$ with a source concentration of $400 \mathrm{ppm}$. The northern most sections (8 to 10) of the test region were injected with ocPDCH at a flow of $53 \mathrm{~mL} / \mathrm{min}$ and $95 \mathrm{ppm}$ source concentration. The injection rates were set such that the internal concentrations beneath the hydraulic barrier would be between 1 and 10 ppm after 5 to 7 days of injection. The injection spacing was approximately 15 feet between tracers. Tracer injection continued until August $16^{\text {th }}$.

The initial tracer injections were allowed to continue for six days prior to starting soil gas sampling. This allowed the site to reach a static condition. On August $13^{\text {th }}$ soil gas sampling was initiated. All 84 sample ports were sampled on August $13^{\text {th }}$ and $14^{\text {th }}$. Sampling was accomplished using battery powered gas sampling pumps, Figure 8. The inlet side of the pump was connected to the sample port tubing. The pump was turned on and purged for 15 seconds. The outlet side of the pump was then connected to the inlet of a gas sampling bag. The valve to the bag was opened and sampling began. Approximately 500 cc of sample was taken over 30 seconds. When the desired

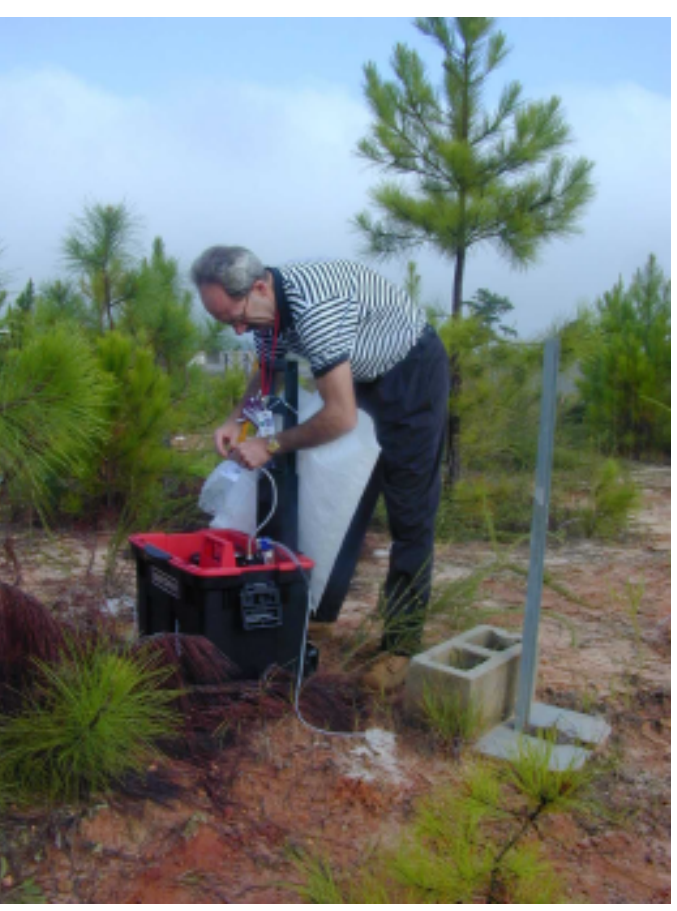

Figure 8 Sampling the soil gases for PFTs using a battery powered pump and gas sampling bags. 
sample was collected the sample bag valve was closed and the bag disconnected from the pump and the pump turned off. The bags were brought to a portable gas chromatograph for analysis.

On August $15^{\text {th }}$, samples of the internal tracer concentrations were also taken. Air samples were taken from the pipe adjacent to the injection pipe in a given pipe cluster. A $50 \mathrm{~mL}$ syringe with a needle attached was used to capture the sample. The needle was pushed through the polyethylene cover sealing the pipe and an air sample was withdrawn into the syringe. The sample was transferred to a gas sampling bag for storage and later analysis.

Samples were analyzed using a field deployable gas chromatograph (GC). The instrument (Figure 9) had dual traps for capturing the PFTs. This allowed individual sample analysis every four minutes. Each day prior to sample analysis, a tracer standard gas was run on each trap of the GC. Blanks and background checks were also performed each day prior to sample analysis. The standard was run twice each day, background checks and duplicates were performed every twenty analyses and blanks were performed every ten samples. In addition, samples were also sent back to BNL to be verified on the laboratory GC.

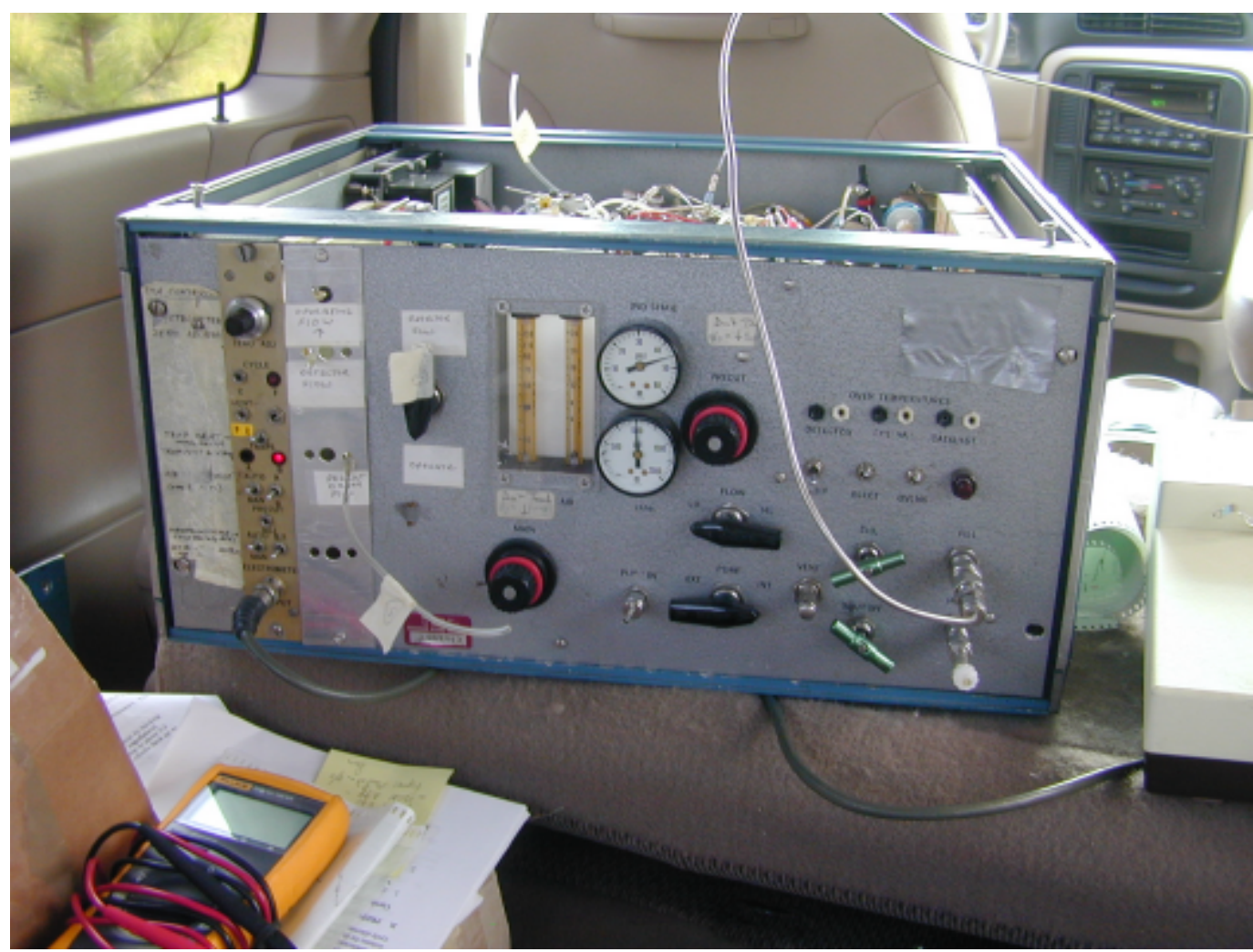

Figure 9 Portable Dual-Trap, Gas Chromatograph used to measure perfluorocarbon tracer concentrations in soil gas samples. 
The GC has two parallel gas circuits running to the detector. Each of these loops has an absorption trap. Gas flows through both traps at all times. One trap leads to a vent while the other trap is analyzed. While the trap is vented, the air sample(s) is injected into the trap. The PFTs (and some other impurities) absorb onto the trap and are held in place. During the analysis mode, the trap is heated which causes the PFTs to desorb and eventually travel through the detector. Several air samples can be loaded on the trap while it is in the vent mode. This allows compositing of samples and a rapid screening of many bags at once. If a composite came up hot (detectable tracer concentrations) then each bag would be sampled individually to find the hot sample(s).

The procedure was to inject gas samples from six bags. This was one half of a column (A-F) in the sample grid. As an example, samples A1, A2, A3, A4, A5, and A6 were all run together. Five mL subsamples were taken from each bag and injected into the same trap of the GC. The samples had to be injected on to one trap while the second trap was being analyzed. Logistically six was the maximum number of samples that could be comfortably injected during the four minute cycle time.

The sample size of $5 \mathrm{~mL}$ allowed us to easily detect $0.01 \mathrm{ppb}$ of the tracers. As the internal concentration goal was 1 ppm this allowed for 5 orders of magnitude dilution across the geosynthetic liner/geomembrane and the 6" to 12" of cover soil below the sample ports. From past experience (1), even small leaks on the order of $1 / 2$ " would be expected to have much less than 3 orders of magnitude dilution over this travel distance.

After the first two days of sampling and analysis, the data showed that the hydraulic barrier was intact (discussed later in results). At this point three induced flaws (see Figure 10) were engineered into the cover. The flaws were placed in the front half of the grid to leave as much of the original cover "intact" as was reasonable. The flaws were introduced by simply driving a 1.25" diameter pipe into the subsurface a distance of four feet. The pipe was removed and the resulting hole was backfilled with a fine sand. In two of the holes, sampling ports were also installed both above and below the geosynthetic liner. In one hole, CH-E Figure 10, a subsidence cavity extending two feet below the Bentomat ${ }^{\circledR}$ layer was found. These ports would give confirmationofinternal tracer concentrations inareas well removed from the injection point.

On August $15^{\text {th }}$ and $16^{\text {th }}$ samples were taken at the sample ports surrounding the flaw locations. The four nearest neighbors to the flaws were sampled resulting in 12 samples taken each day. In addition, the internal concentrations were measured at the access pipes on August $15^{\text {th }}$ and at the port locations installed in the flaws on both days. Tracer injection was discontinued on August $16^{\text {th }}$ at 2 PM. With the low number of samples taken and the expected higher tracer concentrations, no compositing was performed. All samples were analyzed individually. On August $15^{\text {th }}$, samples were taken at random locations away from the flaws to provide confirmation that leaks were not present in other locations. As expected, leaks were not found away from the flaws. 


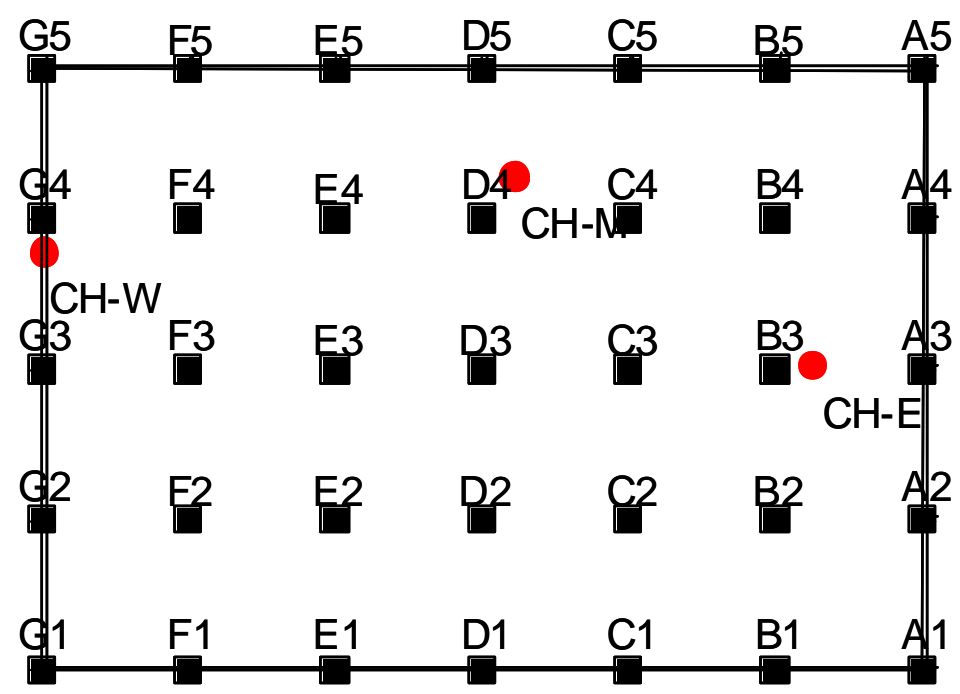

Figure 10 Location of induced flaws.

\section{RESULTS}

All samples from August $13^{\text {th }}$ and $14^{\text {th }}$ were non-detects. Composite air sampling showed all locations to have less than $0.01 \mathrm{ppb}$ of any of the three tracers. The data was entered into a modeling software package, Environmental Visualization Systems (EVS). Figure 11 shows the plan view of the cover test grid with a color-coded mapping of tracer concentrations on August 13 ${ }^{\text {th }}$. Figure 12 shows the side view schematic shown earlier (Figure 4, vertical exaggeration $5 \mathrm{X}$ ) with the tracer concentrations added for both internals and externals. Blue areas represent low $(<0.01 \mathrm{ppb})$ tracer concentrations while pink areas are high concentrations ( 1.0 ppm). Figures 13 and 14 are the corresponding visualizations for August $14^{\text {th }}$. While the internal volume of the cover clearly has high concentrations of PFTs the tracers are not reaching the external ports. The composite hydraulic barrier provided by the geosynthetic clay liner and HDPE membrane remained intact and leak free.

Modeling of diffusion of the gas through the Bentomat@/HDPE layer indicated that the PFT diffusion coefficient through this layer was less than $10^{-8} \mathrm{~cm}^{2} / \mathrm{s}$. Higher diffusion coefficient values would have led to detection of PFTs at concentrations greater than $0.01 \mathrm{ppb}$. Based on previous work (1), the diffusion coefficient of PFTs in sandy soils is approximately $10^{-2} \mathrm{~cm}^{2} / \mathrm{s}$, approximately 6 orders of magnitude greater than through the Bentomat ${ } / \mathrm{HDPE}$ liner. This further supports the contention that the cover was not leaking.

On August $15^{\text {th }}$, after introduction of the flaws, all cavity hole concentrations were around $1 \mathrm{ppm}$. This confirmed that tracer is at high concentrations beneath the Bentomat ${ }^{\circledR}$ liner. Mixing between PMCH and PMCP was evidenced and shows that transport (diffusion) is occurring beneath the liner. The flaws near sample locations B3 and G4 were readily seen (see Figures 15 and 16) by the monitoring network at the nearest port location within a few hours of formation of the flaw. The flaw near location D4 was not observed on August 15 ${ }^{\text {th }}$ (Figures 15 and 16). This was attributed to the slightly lower concentration observed in this flaw as compared to the two other flaws and the short time between creating the flaw and taking the measurement. 


\section{August 13th Sampling Results Top View of Cover Facility}

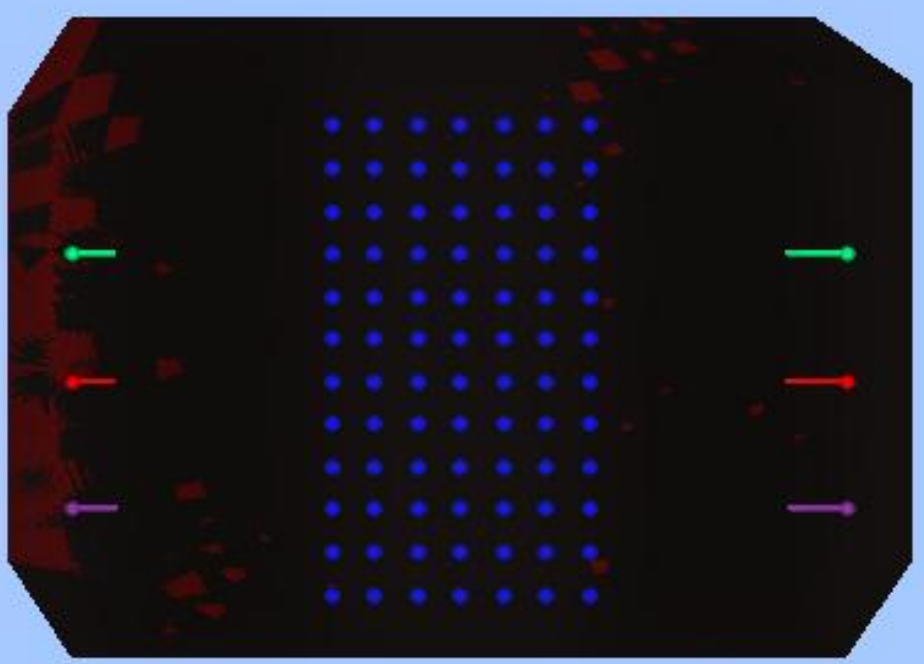

Figure 11 Plan view schematic of Bentomat Cover with PFT concentrations superimposed for August $13^{\text {th }}$.

August 13th Sampling Results Side View of Cover Facility

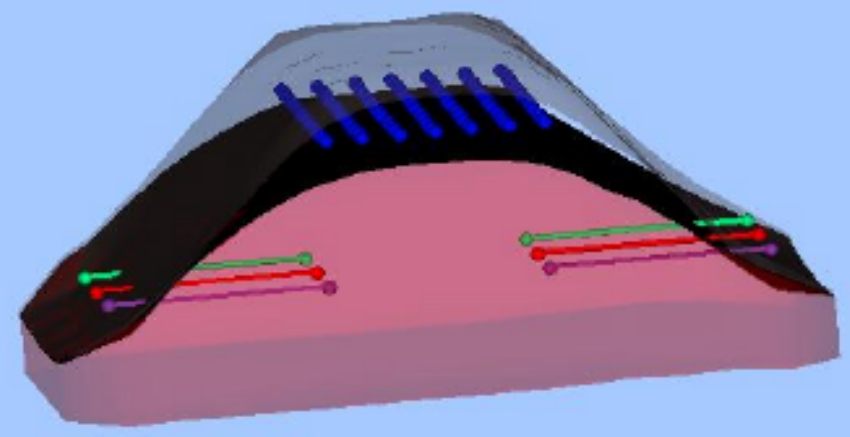

Injection Concentrations > $100 \mathrm{ppm}$ Concentrations above liner $<0.00001 \mathrm{ppm}$

Figure 12 Schematic of Bentomat Cover with PFT concentrations.

Note dark blue points are non-detects and external to the geosynthetic clay liner. Pink is high concentration $(>1.0 \mathrm{ppm})$ of PFTs and is confined to the internals of the cover. 


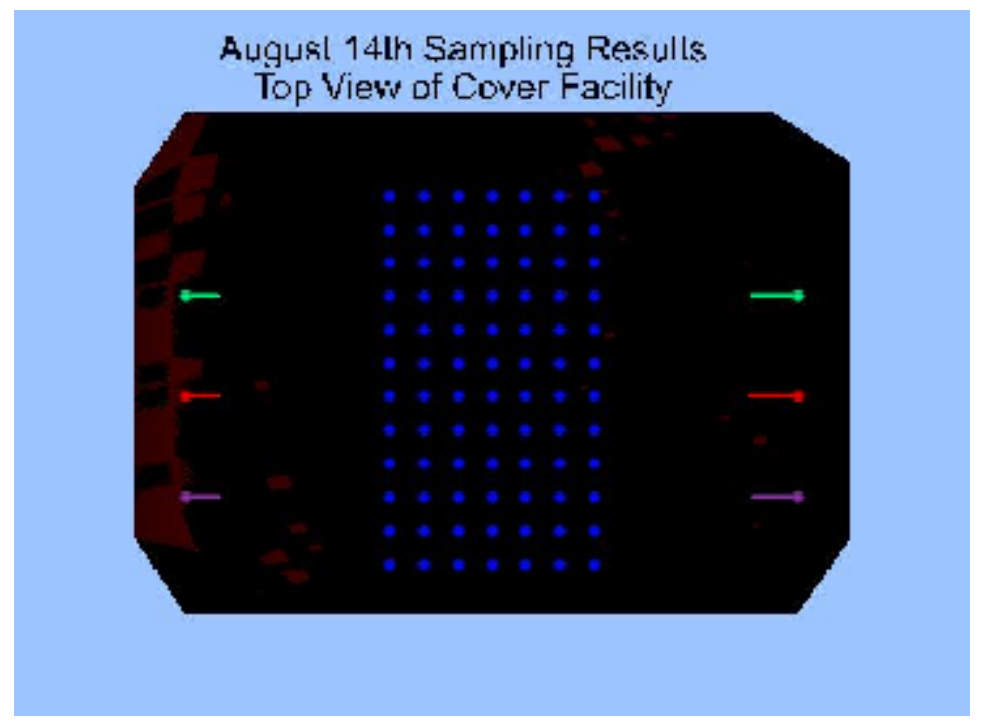

Figure 13 Plan view of cover system with measured PFT concentrations $(<0.01 \mathrm{ppb})$ at all locations on August $14^{\text {th }}$. Injection of tracers beneath the cover depicted in purple $(\mathrm{PMCH})$, red (PMCP), and green (ocPDCH).

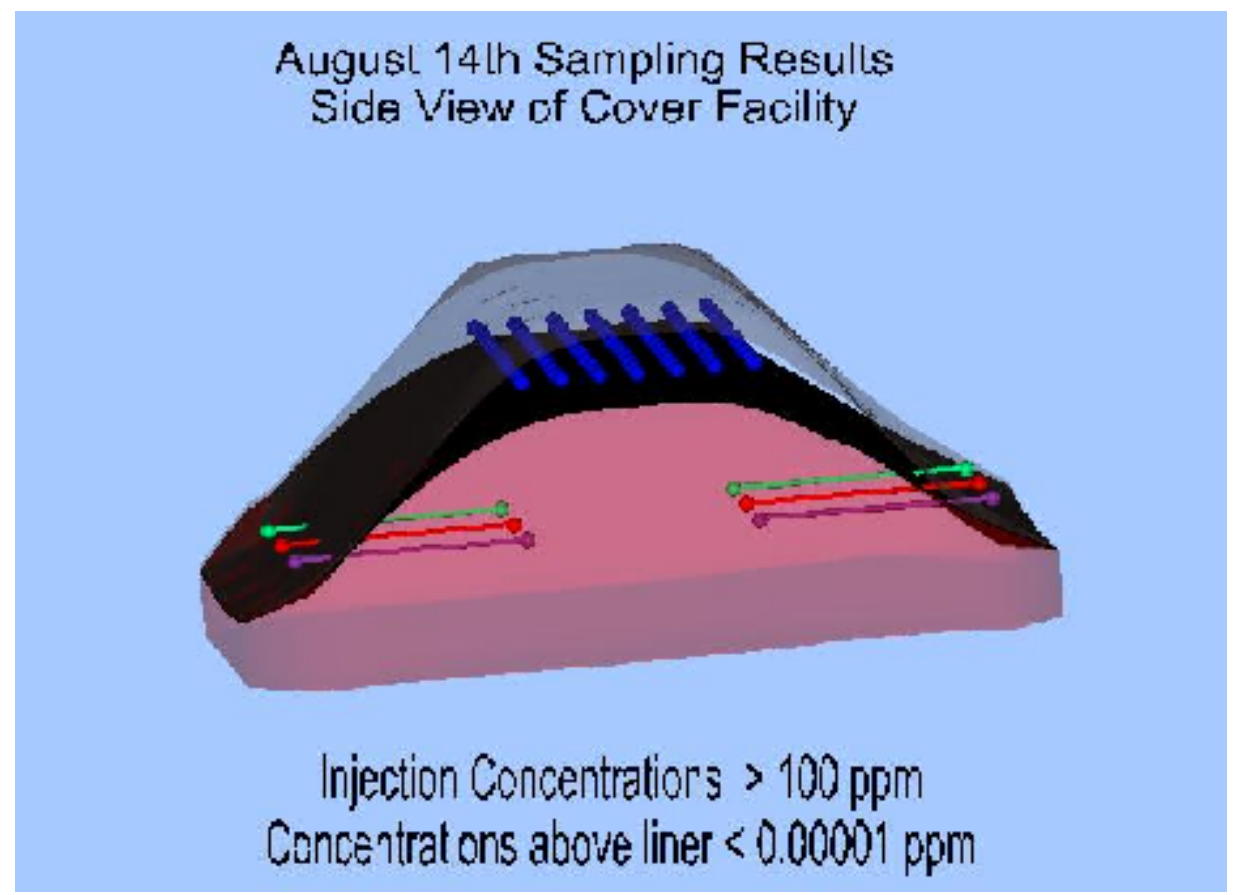

Figure 14 Side view of cover system with concentrations measured August $14^{\text {th }}$ above the liner in blue $(<0.01 \mathrm{ppb})$ and below the liner in pink $(1 \mathrm{ppm})$. 


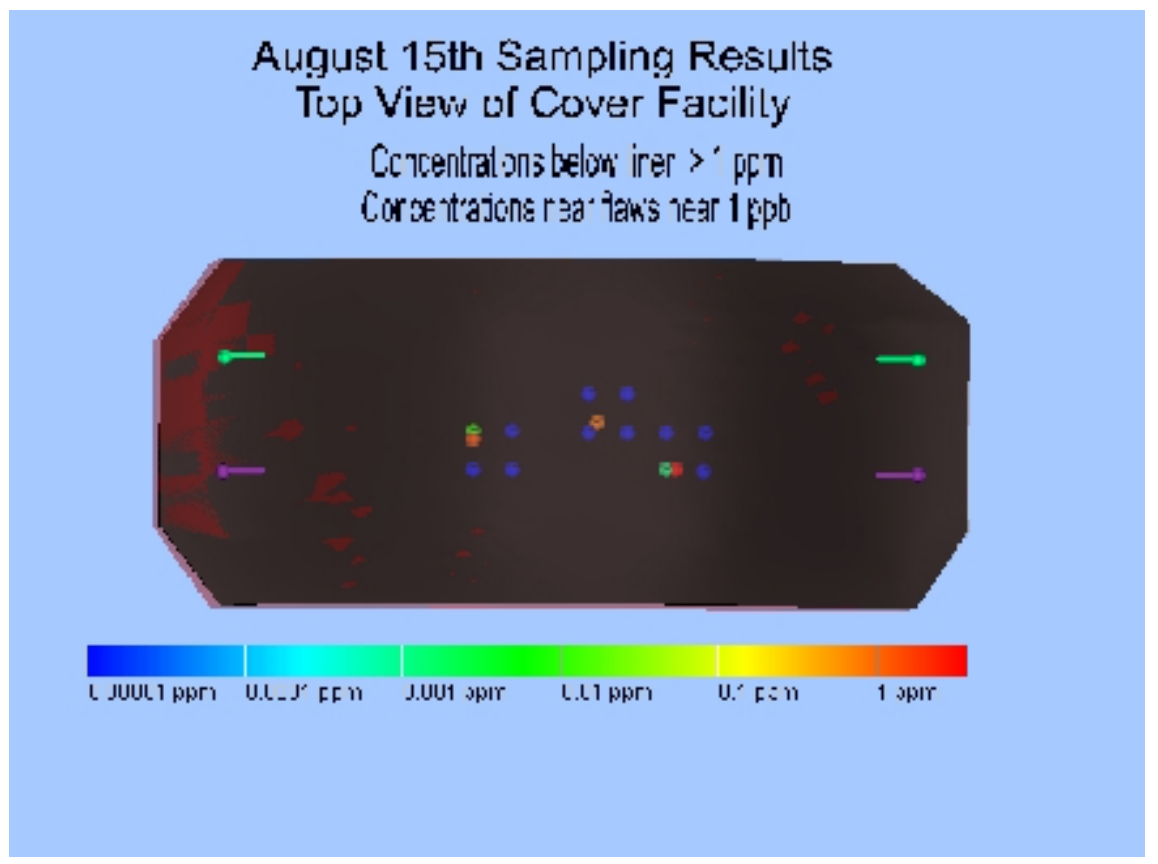

Figure 15 Plan view on August $15^{\text {th }}$ after flaws were introduced in the Bentomat ${ }^{\circledR}$ liner. Orange/red dots indicate location of flaws, green dots indicate detection in monitoring system.

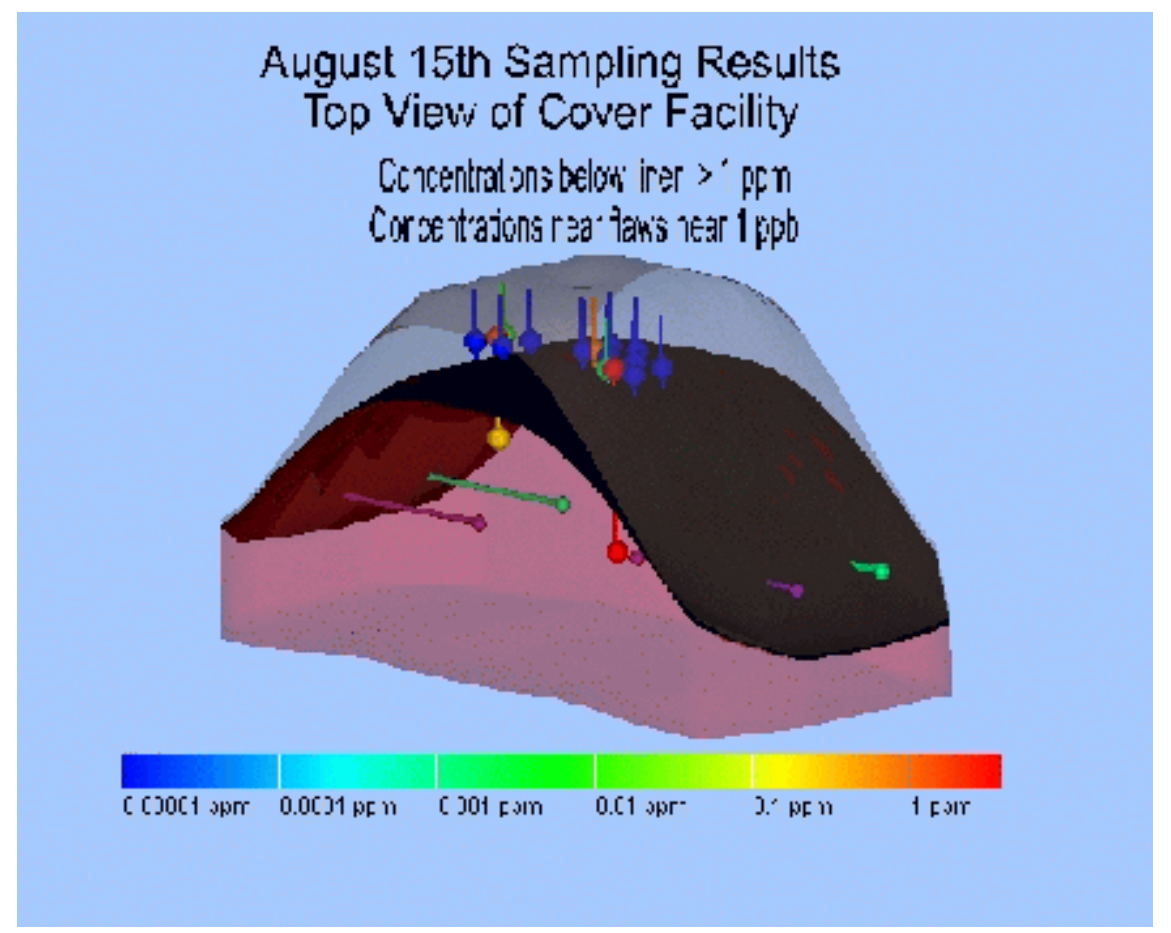

Figure 16 Side view of PFT data on August $15^{\text {th }}$ after introduction of flaws. Color coded sphere below the cover mark flaw locations. 
On August $16^{\text {th }}$ tracer levels beneath the Bentomat ${ }^{\circledR}$ layer remained near $1 \mathrm{ppm}$. Analysis of the data showed all three flaws, with the nearest sample locations showing ppb levels of tracers (see Figures 17 and 18). The ratio of $\mathrm{PMCH} / \mathrm{PMCP}$ in the cavity hole is similar to that seen in the monitoring network. Detection of PMCH and PMCP at the ports near the flaw gave confirmatory data that a leak existed. The data for the two tracers correlated well (see Figure 19).

Overall the concentration difference from internal (beneath the Bentomat ${ }^{\circledR}$ liner) to external (above the Bentomat ${ }^{\circledR}$ liner) was greater than seen in previous subsurface barrier testing and other deep, below-grade tracer studies. This is attributed to the low diffusion rate through the Bentomat ${ } / \mathrm{HDPE}$ liner, barometric pumping, and higher diffusion coefficient in the sand backfilled flaw as compared to the native clay soil. A

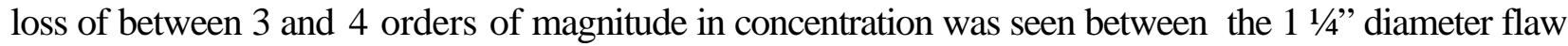
and the monitoring ports located approximately $1-1 \frac{1}{2}$ feet from the flaw. Preliminary modeling of PFT transport from the flaw through the clay top soil indicates the diffusion coefficient $\left(0.002-0.0002 \mathrm{~cm}^{2} / \mathrm{s}\right)$ of the clay soil is one to two orders of magnitude lower than in sandy soils. Thus, although the distance from the flaw to the monitoring port $(\sim 1 \mathrm{ft})$ is less than the distance from the flaw to the surface $(\sim 2 \mathrm{ft})$, the higher diffusion coefficient of the backfilled sand makes transport faster along this pathway. Coupling this with barometric pumping in which the backfilled sand region acts as a chimney, it is clear that concentrations away from a flaw will be low and very sensitive measurement techniques are needed. As this is the most difficult cover systemexpected, in terms of thin surface cover, these data provide confidence that small flaws can be readily detected.

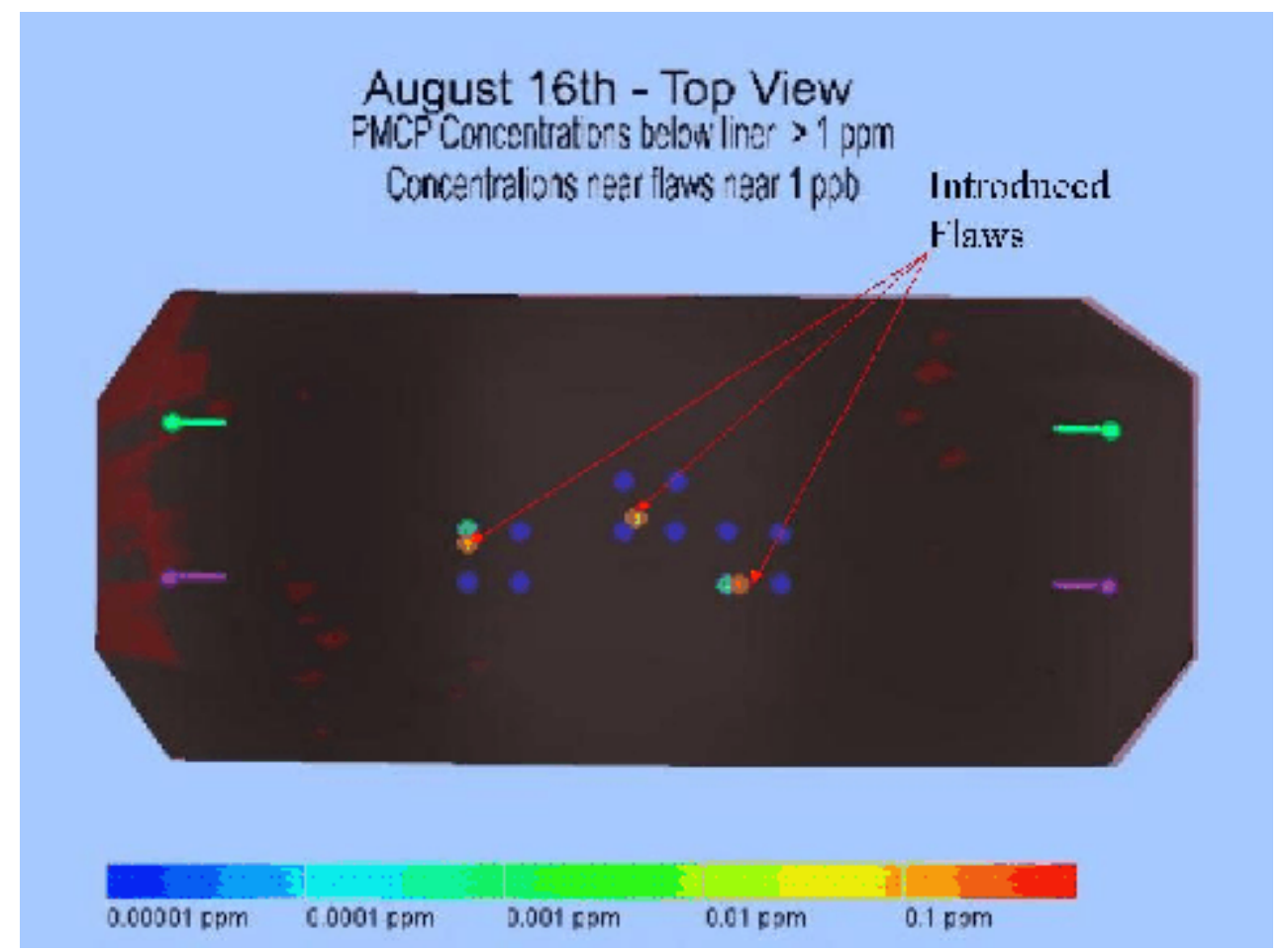

Figure 17 Plan view schematic of Bentomat Cover with PFT concentration superimposed for August $16^{\text {th }}$. 


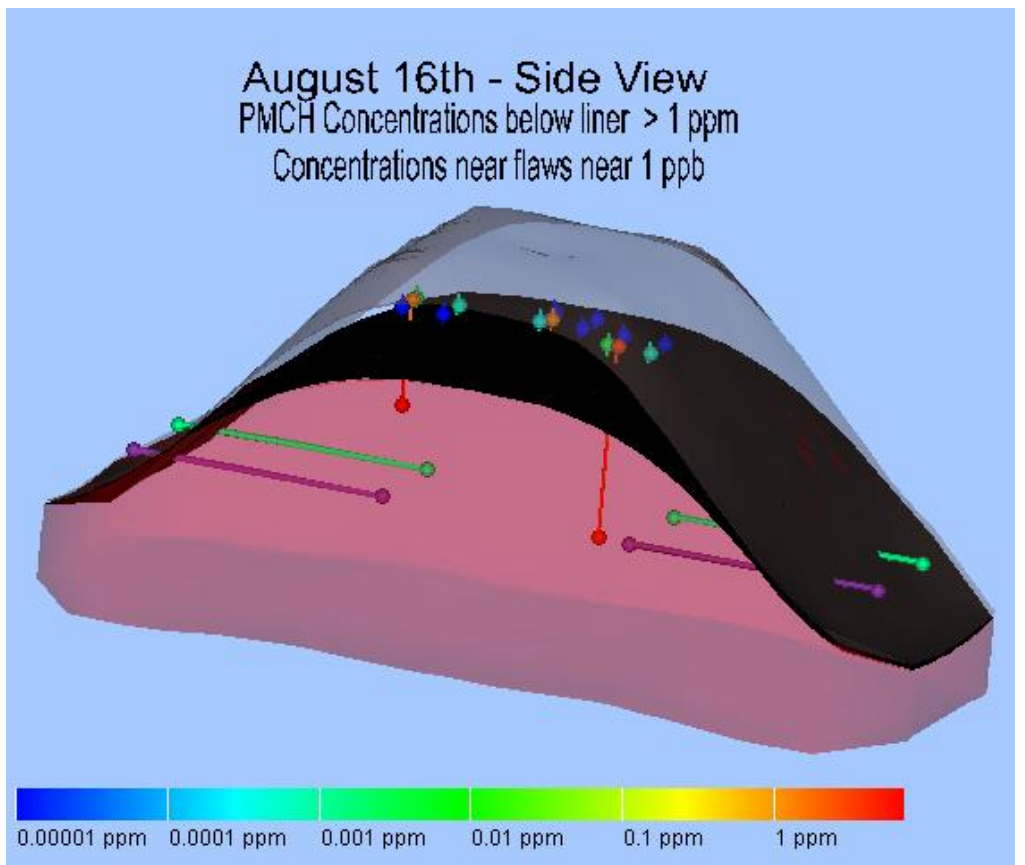

Figure 18 Schematic of Bentomat Cover with PFT concentrations for August $16^{\text {th }}$.

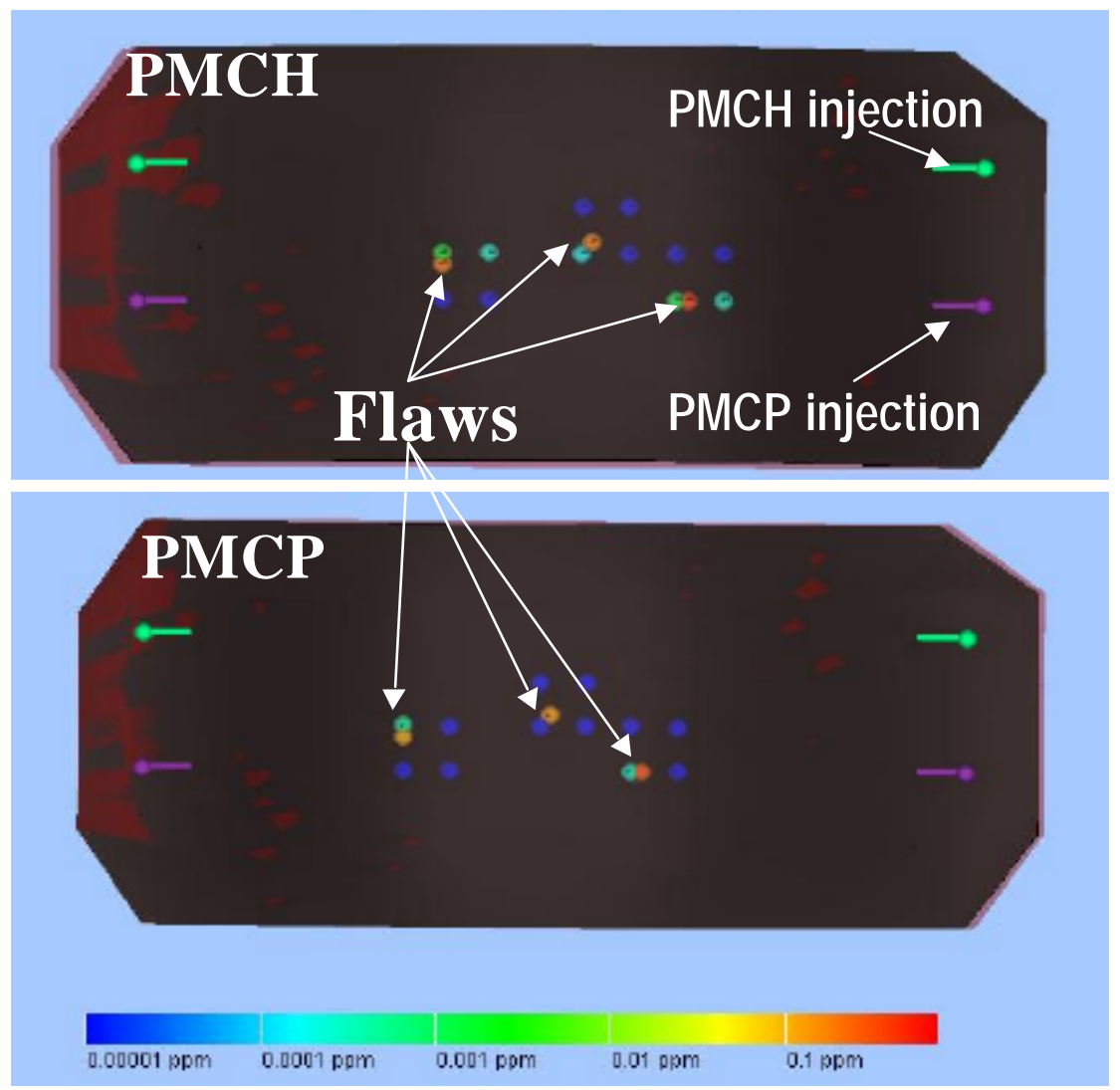

Figure 19 Comparison of $\mathrm{PMCH}$ and PMCP tracer concentrations on August $16^{\text {th }}$. 
The proof-of-concept testing at SRS was successful. Initially, there were no flaws in the Bentomat@ liner. Concentrations beneath the liner were on the order of $1 \mathrm{ppm}$ while concentrations 0.5 to $1 \mathrm{ft}$ above the liner were less than $10^{-5} \mathrm{ppm}$. Three small (1 1/4") flaws were introduced in the cover system. Two flaws were seen within three hours of their creation, while all three flaws were detectable within one day of introduction of the flaw. The results were repeatable day to day and were confirmed by two separate tracers. The Bentomat Test Pad represented a worst case scenario for tracer verification of covers. The cover has a very thin soil layer overlying the hydraulic barrier, less than two feet of soil covered the HDPE membrane in most areas. This allows barometric pumping, wind effects, and atmospheric dilution effects to be maximized.

Inaddition, the use of the field deployable gas chromatograph PFT detector was successfully demonstrated. This unit was able to analyze samples on a four minute cycle down to levels of a few parts per trillion. This provided almost six orders of magnitude span between the concentrations beneath the liner (ppm) and nondetectable levels. This is more than sufficient to accurately determine the presence of a leak. Up to six sampling locations were composited to speed analysis time when examining for leaks.

Small flaws were detected without having to increase the internal concentrations of PFTs over normally used values (based on barrier verification). If the dilution effects had been greater, the flow rate of the tracers could have been increased or higher tracer concentration source tanks could have been used. The internal concentrations could be raised from 1-10 ppm to $1000 \mathrm{ppm}$ or greater if needed. This provides several orders of magnitude increase in sensitivity to leak detection. It also increases the cost of the technology slightly (increased tracer cost), makes analysis a little more complicated as one needs to watch out for "swamping" the GC detector (lost time waiting for detector to clean out), and increases greenhouse gas releases.

The existing low internal concentration requirements allow for greater design flexibility. For example, very fine tubing can be used to deliver the small amount of tracer required. The smaller diameter tubing can be fitted to the geotextiles prior to installation at the cover site. Low tracer concentration requirements also allowdifferent methods of tracer introduction (i.e., slow release permeation cells implanted under the cover). There are many advantages to remaining at the lower flood concentrations.

The multiple tracers available with PFTs (and not with competing systems) allow greater flexibility in experimental/installation design, yields redundant (re: confirmatory) data and gives information on internal transport pathways not available from single tracer systems. This advantage is magnified when the PFT technology is applied to multi-layer cover systems. With multiple layers there may be convoluted leak pathways. Flaws in two layers may not be aligned and the transport pathway may have a horizontal aspect. In this case, single tracer technology would see only the exit hole. Multiple tracers allow different tracers to be injected between layers. With monitoring ports placed within each layer it is easy to tell flaw location for each layer. Even having only monitoring ports above the final layer, the spectrum of tracers coming from an exit hole can be used to determine which layers are faulted and the concentrations can be used to estimate how convoluted the travel pathway is. 


\section{REFERENCES}

1. Sullivan, T. M., Heiser, J., Gard, A., and Senum, G., Monitoring Subsurface Barrier Integrity using Perfluorocarbon Tracers, J. Environ. Eng. 124, 490-497 (1998). BNL-66156

2. Heiser, J., and Dwyer, B.P., "Summary Report on Close-Coupled Subsurface Barrier Technology - Initial Field Trials to Full-Scale Demonstration", Brookhaven National Laboratory, Upton, New York, September 1997, BNL-52531.

3. D'Ottavio, T.W. and Dietz, R.N., "Radon Source Rate Measurements using Perfluorocarbon Tracers", Indoor Air '87: the 4th International Conference on Indoor Air Quality and Climate, Berlin, Germany, August 17-21, 1987.

4. Horn, E.G., R.N. Dietz, R.M. Aldous, G. A. Leadon, L.J. Honan, and K.K. Seiffert, EPRI 1991 PCB Seminar, Baltimore, MD, 1991.

5. Serrato, M.G., Bentonite Mat Demonstration, Final Report, Westinghouse Savannah River Company, Aiken, SC, December 1994, WSRC-TR-94-0618 